\title{
Telling Tales: George Stroke and the Historiography of Holography
}

\author{
Sean F. Johnston
}

The history of holography, the technology of three-dimensional imaging that grew rapidly during the 1960s, has been written primarily by its historical actors and, like many new inventions, its concepts and activities became surrounded by myths and myth-making. The first historical account was disseminated by the central character of this paper, George W. Stroke, while a professor of Electrical Engineering at the University of Michigan. His claims embroiled several workers active in the field of holography and information processing during the 1960s, but transcended personality conflicts: they influenced the early historiography of holography and the awarding of the Nobel Prize for Physics to Dennis Gabor in 1971. An extended discussion of these episodes, based on archival research, publications analysis and interviews with participants, reveals the importance and extraordinary allure of intellectual priority for practicing scientists, and how its history and explanations are woven from multiple accounts and contemporary interpretations.

Keywords: Holography; Historiography; Nobel Prize; Dennis Gabor; Priority Dispute

\section{Introduction}

'Origin myths' in science and technology can seldom be tracked closely, owing to the dearth of available evidence concerning the construction, subliminal or intentional, of such accounts. However holography, the technology of three-dimensional imaging that grew rapidly during the 1960s, provides such an opportunity. A nascent subject young enough to have many of its early participants still available for direct contact, holography illustrates how the history and explanation of a subject are woven from multiple accounts and contemporary interpretations.

Like many new sciences, the concepts and activities associated with holography became surrounded by myths and myth making. A burgeoning field offers many opportunities for intellectual exploration, professional advancement and corporate

Sean F. Johnston is Senior Lecturer in Science Studies at the University of Glasgow. Correspondence to: Sean F. Johnston, University of Glasgow, Crichton Campus, Dumfries DG1 4ZL, UK. Email:S.Johnston@crichton.gla.ac.uk 
profit. While they were little publicly documented at the time, some such cases of conflict became widely known, and, at times, historically distorted and privately mythologized. The cases were most frequent during the first decade of holography's explosive expansion, when there were few precedents and everything to play for.

The first historical account was disseminated by the central character of this paper, George W. Stroke, while a professor of Electrical Engineering at the University of Michigan. Stroke's version of the history supported his own priority claims, and the contentions embroiled several workers active in the field of holography and information processing during the mid-1960s. They transcended mere personality conflicts, however: Stroke's claims strongly influenced the early historiography of holography and the awarding of the Nobel Prize in Physics to Dennis Gabor in 1971. Just as importantly, his claims in the public domain denied the Prize to other contenders, particularly rivals at the Willow Run Laboratories at the University of Michigan whom Stroke categorized as narrowly trained engineers. An extended discussion of these episodes reveals the importance and extraordinary allure of intellectual priority for practicing scientists. Establishment of precedence can provide professional and social status, bring support in the form of a succession of research contracts and consultancies, and can mean the difference between a reputation that long outlives its subject, or a subsequent career in obscurity. The disputes concerning the history of holography also reveal the tenacity of 'insiders' accounts' and the difficulty in deconstructing such claims. Holography can serve as a caution to historians who frequently have fewer sources of evidence for unravelling contemporary accounts and establishing historical veracity. The case is an example of the additional constraints on scientific openness during the Cold War period, and the incompleteness of reviewed papers in documenting priority and the development of concepts. The title therefore is intended to convey two meanings: 'telling tales' in the sense of 'stories that are revealing' and, additionally, 'telling tales' in the sense of 'creating myths'.

This study is part of a larger project exploring the history of holography in wider culture. The research employed archival and published sources and interviews with practitioners. This paper is based on the information provided by some 19 early practitioners who were colleagues, students or workers in the field, as well as archives at Imperial College, London, the MIT Museum, Cambridge, USA, and the Bentley Historical Library, University of Michigan, Ann Arbor, USA. ${ }^{1}$

Of the several thousand energetic workers who were active in holography over its first 50 years (which can be estimated conservatively as expending some 20,000 personyears of R\&D labour), scarcely 5 percent achieved recognition beyond their active subfield; of these, only a handful gained public recognition. The most prominent of these, and at the centre of early historical accounts through the 1960s, were Dennis Gabor, Emmett Leith, and George Stroke.

\section{Background of Holography}

Holography since the mid-1960s has developed as a sophisticated means of recreating a convincing three-dimensional image of an object, complete with parallax (the ability 
to 'look around' from various angles) and, in some variants, full colour and motion. This remarkably lifelike 'wavefront reconstruction' is achieved by first recording a 'hologram', an interference pattern created by the superposition of light reflected from the object and light coming directly from the light source. A laser, which has the requisite 'coherence', or stability of wavelength and phase, is normally employed, but a monochromatic lamp can also be used in certain circumstances. When appropriately illuminated, the hologram will recreate a close copy of the wave pattern of light that reflected from the original object. Numerous extensions and applications were developed, of which the most significant have been 'holographic interferometry', which can measure exquisitely fine motions or deformations of objects; 'display holography', which was taken up by artists and entrepreneurs from the 1970s; and, 'embossed holograms' which became ubiquitous from the 1980s as security devices on credit cards and packaging. The subject spawned an unusually broad range of practitioners, and, perhaps because of the speed of expansion, generated historically naïve and increasingly simplified accounts of its genesis. ${ }^{2}$

All accounts agree that the technique was conceived by Dennis Gabor in 1947 as a particular solution to the problem of poor imaging in electron microscopy, and that it was reborn as a more powerful and general invention at the University of Michigan in the early 1960s. An alternate formulation was conceived in the late 1950s/early 1960s by Yury Denisyuk, who was then studying for a Kandidat in physics while working at the Vavilov State Optical Institute in Leningrad. Denisyuk, however, was unable to pursue the technique, which he termed 'wave photography', beyond his limited thesis research until holography was popularized in the west. ${ }^{3}$

\section{Gabor, Leith and Stroke: Intellectual and Institutional Contexts}

Besides the Vavilov Institute, which was peripheral to the early western accounts of holography, two sites were crucial: an industrial electrical laboratory in Rugby, England, and a classified research laboratory in Willow Run, USA.

Dennis Gabor (1900-1979), an émigré Hungarian, had obtained his $\mathrm{PhD}$ in Germany for work on high-speed oscillographs, and later worked at Siemens \& Halske in Berlin as a research engineer. At the British Thomson-Houston Company (BTH) in England from 1934, he developed inventions ranging from gas discharge lamps, infrared detection of aircraft, pulse-compression of communication signals, and threedimensional cinema to what he called 'microscopy by wavefront reconstruction'. The melding of foundations in electrical and optical theory and in practical invention suggests his range and depth.

Gabor's experimental work on wavefront reconstruction, which he initially dubbed 'holoscopy', was performed at BTH with an assistant, Ivor Williams, from the autumn of 1947 to early $1948 .{ }^{4}$ He had been discussing means of improving the imaging of the first commercial electron microscopes with an associate at a sister company, Michael Haine of Associated Electrical Industries (AEI), since 1944. Gabor envisaged recording the pattern created by electrons diffracted by a microscopic object and interfering with undiffracted electron waves. ${ }^{5}$ The interference pattern, which he called a 'hologram', 
would then be used to reconstruct an enlarged image of the object by illuminating it with coherent light. Unlike electron microscope lenses, the glass lenses for visible light sources could correct for optical aberrations. Gabor obtained the patronage of Sir Lawrence Bragg, who had earlier made his reputation from studies of x-ray diffraction. ${ }^{6}$ Yet Gabor's scheme suffered severe practical drawbacks: electron beams in the available electron microscopes proved insufficiently coherent, and could generate far less interference than Gabor had hoped. Similarly, the visible light sources then available had very limited coherence, and so would be capable of reconstructing the image of only a narrow class of objects. Worse still, the optical arrangement that Gabor employed introduced seemingly unavoidable contamination of the image by an out-offocus 'conjugate' image, which reduced the quality considerably. ${ }^{7}$

Gabor moved to a Readership in Electrical Engineering at Imperial College, London, in 1949, a post supported strongly by his work on what he and others referred to alternately as 'microscopy by wavefront reconstruction', 'interference microscopy' or merely 'the holoscope'. His colleagues at AEI continued the development of electron-beam diffraction patterns, supported by one of the first grants from the Department of Scientific and Industrial Research (DSIR) for research by an industrial company. By 1952 they had become pessimistic, and by 1954 Gabor, frustrated to the point of desperation, was pleading with the AEI workers to continue to study ways of improving their apparatus. ${ }^{8}$ In his turn, Gabor and a postgraduate student worked on further developing the optical reconstruction side of the scheme during 19541956. Nevertheless, by 1958 both parties had given up, with T.E. Allibone, head of research at AEI, classifying the concept as a white elephant. ${ }^{9}$ Gabor pursued other projects more clearly associated with electrical engineering, such as information theory in communications and the behaviour of plasmas for containment of fusion reactions. Acrimony flared again when Gabor publicly blamed the failure of interference microscopy merely on the stability of electron microscopes, and Allibone retorted that 'the failure of the whole principle of electron microscopy by reconstructed wave fronts was the confusion caused by the second image'. ${ }^{10}$ While a handful of researchers made limited progress on this incapacitating optical problem, by the end of the 1950s 'interference microscopy' was seen as a marginal idea of little applicability or practicality. ${ }^{11}$

While research on wavefront reconstruction was waning in England, it was being reinvented in America. After the Second World War, the University of Michigan founded laboratories at the Willow Run Airport, near Ann Arbor, Michigan, supported, like those at some other American universities, mainly by military contracts. Project MICHIGAN, the largest such contract administered by the University, led the Willow Run Laboratories (WRL) to establish a radar lab in 1954 that was intended to develop synthetic aperture radar (SAR) as a high-resolution imaging technology. ${ }^{12}$

Emmett Leith (1927-), a Research Assistant at WRL, having taken undergraduate optics courses as a Physics major at Wayne State University-in physical optics, spectroscopy, x-rays and crystal structure-and completing BS (1949) and MS (1952) degrees there in physics, found himself well placed in an environment dominated by electrical engineers to undertake his first major task there: the preliminary study of the 
optical processing of radar data. ${ }^{13}$ He discovered that the SAR data, recorded on photographic film as an unintelligible pattern, had similarities to diffraction patterns made by interfering beams of light. Leith was struck by the idea that light waves diffracted by the data record were really optical replicas of the original radar waves:

The most interesting thing along the way was, when I was looking at the results of the anal-
ysis, something suddenly dawned on me, which I thought was most astonishing: if you
look at the data record and considered it being illuminated with the beam of coherent light,
the field that emanated from it in the first diffracted order was in fact an optical reconstruc-
tion of the original radar field which was captured by the synthetic aperture radar as it flew
along its flight path. ${ }^{14}$

He developed the theory of SAR from this physical optics viewpoint, rather than the concepts then familiar to the radar world such as cross-correlation and Doppler filtering. By early 1956 he had drafted a quarterly report to the sponsor that summarized this perspective. ${ }^{15}$ The idea languished, however, being met with complete indifference by the community of SAR researchers. Like Gabor's earlier publications, the memo was abstruse and its physical optics approach was a radical departure from the communications theory familiar to electrical engineers.

Between 1957 and 1960, a practical SAR system was developed at WRL. The coterie of radar researchers now recognized optical processing as an elegant and widely applicable method, and the WRL Radar and Optics Lab continued to further explore its possibilities. ${ }^{16}$ Research on wavefront reconstruction, a sideline of Leith's SAR work, could be accommodated because of the size of the contract, Leith's regular generation of new ideas, and the willingness of the sponsor to seek new approaches. From 1960, he and a junior WRL colleague, Juris Upatnieks (1936-), began to duplicate Gabor's experiments partly because Upatnieks did not yet have military clearance to work on classified projects. They soon developed methods of removing the contamination of the images of the hologram by applying communication theory to the optical problem, tackling the nuisance of overlapping images by introducing a 'carrier wave', which in optical terms amounted to angularly separating the interfering waves of the hologram. The result was a dramatically improved technique that was later dubbed 'off-axis holography'. The pair produced two papers on the improvements they had achieved over the previous six months, written during late 1960 and the summer of 1961. In the first, they described the off-axis geometry for wavefront reconstruction and how it avoided the conjugate image problem that had plagued Gabor and his successors; in the second paper, they discussed wavefront reconstruction in terms of communication theory. ${ }^{17}$ But there the project was interrupted: Upatnieks took a leave of absence for military service.

The University of Michigan had recognized for some time that the Willow Run Laboratories, while generating considerable income, were poorly integrated with academic functions. Although several of the Electrical Engineering department professors held joint appointments with WRL, it remained physically isolated from the campus 15 miles away. Administrators arranged for a gradual merging of the WRL classified activities with undergraduate teaching. One move in this direction was the establishment of a chair in Electro-Optical Sciences, and the appointment of George Stroke 
to fill it. In negotiating with Stroke, William Dow, head of the Electrical Engineering Department explained:

Our need for competence in Applied Optical science is the basis for our interest in you. My initial interest in your capabilities arose because optical science is rapidly becoming of great importance in dealing with new electronically-related devices, systems, and observational data inputs. The microwave spectrum merges through infrared into the optical spectrum. Expanding systems uses of the infrared spectrum and of optical quantum electronics-lasers-require of electrical engineers an understanding of optical science not heretofore necessary. Quite apart from that, optical data processing principles and techniques that originated here are giving a new multi-thousand-channel processing resource that our students and our research staff must be able to use...thus I came to feel that your presence among us would substantially strengthen our research and instructional capabilities in an area common to basic and applied science that is making a powerful new impacts. ${ }^{18}$

Publicly, James Wilson, acting director of the Institute of Science and Technology, which oversaw WRL, announced that Stroke's post was intended to promote the transfer of expertise from the hidden world of contract research to academe, enabling 'graduate students to work with modern developments in optics which have been advanced in industry and in defense and the space programs conducted by the federal government'. Indeed, Wilson added,

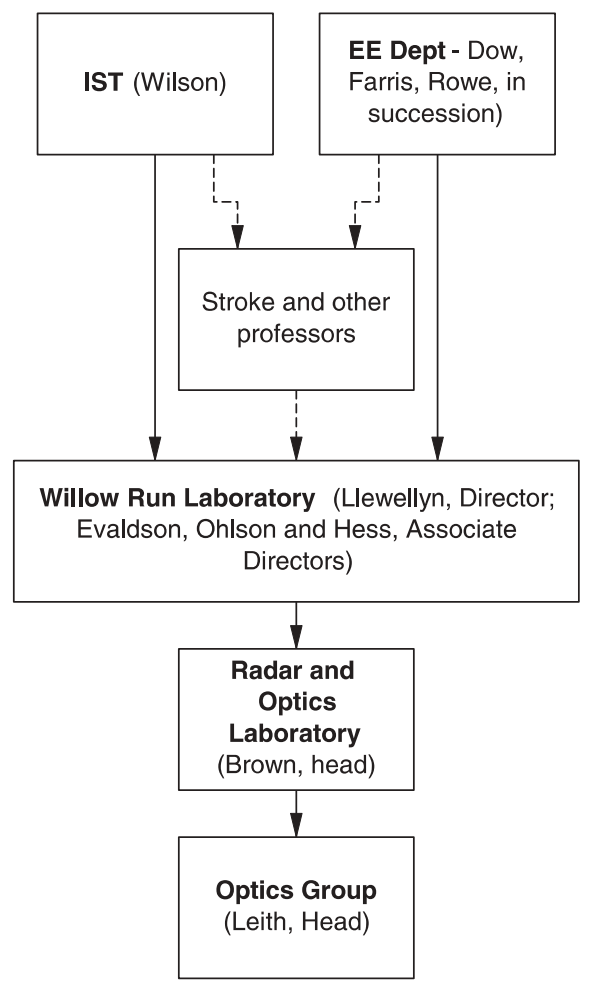

Figure 1 Administrative Structure at the Institute of Science and Technology, University of Michigan, During the Mid-1960s. 
The University is pioneering in this field. New knowledge in optics is being developed and used in industry with dramatic results-especially in electronic information processing, light amplification and control with lasers, and communications. Universities are doing research in this field, but little in the way of formal teaching related to it. ${ }^{19}$

George Stroke (1924-) appeared to be an ideal candidate. Like Gabor, Leith and a handful of other post-war researchers, Stroke had a career background that straddled the disciplines of physics and electro-optical engineering. Born in Yugoslavia, he spent his youth in France and the period 1943-1947 as an apprentice optical worker in British Palestine, completing an engineering optics diploma at the École Supérieure d'Optique in Paris in 1949. In 1952, he immigrated to the US and obtained a post as a Research Associate with George R. Harrison, Dean of Science at MIT and Head of its Spectroscopy Laboratory. ${ }^{20}$ There his technical experience was deepened considerably: he assisted in the development of an interferometric servo-controlled ruling engine, a sophisticated device for precisely scribing a glass plate with fine, parallel lines to create a diffraction grating, itself intended as the heart of a spectrometer to disperse light into a spectrum. ${ }^{21}$ Stroke completed work on the theory of diffraction gratings for his Docteur ès Sciences, received in Paris in 1960, gradually to broaden his training from engineering optics to mathematical physics. ${ }^{22}$ He returned to MIT with a broader circle of academic contacts and solid mathematical training added to his practical experience in engineering optics, but had a gradual falling out with G. R. Harrison. ${ }^{23}$

\section{'Lensless Photography'}

Upon Juris Upatniek's return to WRL in November 1962, he and Leith attempted to make more sophisticated holograms, first of grey-scale transparencies (all previous holograms had employed stark black-and-white images only). By the following summer they had obtained excellent results, and prepared a paper for publication. The impressive quality of these two-dimensional greyscale images suggested a news story to the Optical Society of America (OSA), which was due to publish it. ${ }^{24}$ The public relations department of the parent organization, the American Institute of Physics, came up with the theme of 'lensless photography' for a press release. Newspapers across America picked up the story in early December 1963, usually with few mutations.

The press release itself reshaped the meaning of Leith's and Upatnieks' accomplishment via both its text and illustrations. The text emphasized that their technique was a sophisticated form of photography. It translated the unfamiliar components of wavefront reconstruction into more conventional objects: a 'blurred photographic negative', an 'optical system', 'projector-like device', 'projection screen' and 'camera-like device'. The illustrations of the diffraction pattern (hologram) and its reconstruction were unfortunately of identical size and format, confusingly suggesting that one mapped directly onto the other. This identification was further conflated by the description of the hologram as a 'blurred image'.

The laser had not been a part of the initial work performed by Leith and Upatnieks, although a pervasive mythology was to arise concerning it. ${ }^{25}$ The Optics Group had no experience with lasers at this point, but nearly a decade of highly relevant experience 
with the filtered mercury arc lamp, the most coherent light source previously available. The Optics group at WRL procured lasers on the open market for evaluation in late 1962, and Leith and Upatnieks were able to use it for trial experiments the following July, finding the light source bright but troublesome because of stray interference. ${ }^{26}$ In November they tried again, and obtained their first three-dimensional holograms-a dramatic development.

This step from two- to three-dimensional imaging was, suggests Leith, intellectually trivial, which may account for its passing mention in the popular press. Similarly, Upatnieks recalls:

The property of holographic images being three-dimensional was obvious to us and I am sure to Prof. Gabor. In fact, it was so obvious that initially we considered it to be a waste of time to show it experimentally... [But] once we succeeded, we were fascinated by the reality of the image and spent hours looking at it, and showed it to our colleagues. ${ }^{27}$

By early December, when the wide coverage of their holograms of grey-scale transparencies filled newspapers, Leith and Upatnieks were beginning to show the exciting new results to colleagues and to give hints to the press. The first published description of three-dimensional imagery appeared three weeks later in Electronics. Mentioning possible applications, it ended with a hitherto unmentioned capability:

Leith points out that it is possible to record opaque three-dimensional objects, using reflected light, and that this has been done. The image reconstructed from the hologram can be photographed, completing the second step. In addition it is possible to view the reconstructed image directly by placing the eye so as to intercept the light emerging from the hologram. A three-dimensional projection is formed, having the effect of stereo projection, though only one hologram is used. ${ }^{28}$

Another early attempt at description appeared in a Sunday article in the local Ann Arbor newspaper. Besides descriptions of side-looking radar and 'death ray' lasers, the article devoted a few paragraphs to holography:

The light bounces from the subject, into a mirror and onto film. The result is a transparency that looks to the eye like a buttermilk sky. But when laser light is played upon it, the original scene takes shape in three dimensions. An unusual property of the transparency is that the whole or any part of it contains the entire picture. Tear it up and any fragment of it will reveal the total picture under laser light. ${ }^{29}$

Over the following three months, the popular press reports and word-of-mouth accounts of visitors began to raise more attention, but the galvanizing event was a presentation at the final session of the Spring meeting in Washington, DC, of the Optical Society of America in April 1964. There, in a session on 'Information Handling by Optics', Upatnieks presented their 15-minute paper and subsequently displayed the hologram of a toy train to a long queue of optical scientists which trailed out of a hotel suite, down the hall and around the corner. ${ }^{30}$

From the hidden world of military contract research, Leith and Upatnieks were suddenly catapulted to the public stage. 'Lensless photography' or 'holography', a term coined in 1949, filled newspapers and magazines. ${ }^{31} \mathrm{WRL}$ administrators provided seed money and agreed to expedite the clearance of papers for publication, and allowed all 
members of the lab to do work on the subject. A subsequent meeting in Boston on 'Information Processing Technology' in November 1964 further publicized the Willow Run advances, but simultaneously clouded the achievements with rival claims from their new colleague at the University of Michigan, George Stroke.

\section{Leith, Stroke, and Priority Disputes}

Stroke had initially been recruited for the Chair in Electro-Optics in 1962, and visited WRL that summer. His contract negotiations had continued for a year, however. He had been preceded by his former MIT undergraduate student, Arthur Funkhouser, who worked at WRL through 1963, but Stroke accumulated a small team of students and technicians during 1964-5 for his new Electro-Optical Sciences Laboratory at the U-M North campus in Ann Arbor.

On his arrival at U-M in August 1963, Stroke apparently had foreseen little involvement with Willow Run's ongoing research on wavefront reconstruction. He proposed to fit into the ecology of the University by pursuing the areas he knew best (gratings and optical instrumentation), taking up new areas that he perceived as cognate (relativistic optics and quantum electronics), and engaging in some shared work concerning communications. From late summer 1963, however, Stroke began to visit WRL about twice a month, taking particular interest in the work of Leith and Upatnieks and spatial filtering research being undertaken by Anthony VanderLugt.

In these visits in the first months after taking up his University of Michigan post, Stroke suggested that the Willow Run work on wavefront reconstruction be combined with, or transferred to, his planned lab, and to seek joint funding from the National Science Foundation (NSF), signing notes of agreement to this effect in early December-just days, in fact, after the press releases on lensless photography. ${ }^{32}$ Leith and other members of the WRL Optics Group felt that the aim of bringing the work to an academic environment was worthwhile, and most were pleased to participate. Stroke's relative prominence in optics contrasted with those at Willow Run, who for the most part were, in Leith's words, 'rather narrow specialists in a relatively unknown area of optics' ${ }^{33}$ Nevertheless, they saw Stroke's knowledge as peripheral to the expertise developed at Willow Run. Stroke, however, had been complaining privately to administrators about competition for funding and support and, indeed, operating culture, from Willow Run:

It might be added, unfortunately, that the lack of a Ph.D. by such people as Leith, is not only a lack in adequate terminal training in areas outside narrow specializations, but it shows up in a lack of appreciation of the process of Ph.D. thesis and more generally basic educational responsibilities and basic scientific research work, such as those on which a great university must insist. ${ }^{34}$

Overt disputes concerning the relative status of Stroke's Electro-Optical Sciences Lab and the Radar and Optics Laboratory of WRL began almost immediately. The NSF grant application, closely based on Leith's unsuccessful proposal submitted the previous summer to the US Army Research Office, was found to the surprise of WRL administrators to list George Stroke as project Director and senior author. ${ }^{35}$ Academic priority was not the only issue. The potential income from a successful 
patent for off-axis holography was becoming clear to all participants. Stroke wrote to the Chairman of the U-M Research Policy Subcommittee early in 1964 as his disputes with Leith and Upatnieks were gestating, suggesting that a windfall of money for Willow Run researchers would strain academic relations. ${ }^{36}$

Within a few months, the Director of the IST was warning the Vice President of Research of problems to come, noting that Prof Stroke

came to Ann Arbor either completely unprepared to appreciate the long history of optical work at Willow Run and its reputation and seniority in its special fields, or unaware of its abilities and reputation...In any case, he elected to build on the Willow Run work but has been singularly unsuccessful in carrying the Willow Run people with him. They, I feel rightly, wanted to be full partners and co-equals and he has felt that tenure and departmental connection on his part leaves them subordinates...He seems temperamentally unsuited to being the bridge and campus leader that the Willow Run people wanted. ${ }^{37}$

Most significantly, Stroke began voicing his concern that he was not receiving due recognition for contributions to the work at Willow Run, first privately to Leith's superiors, and then publicly. He claimed that he had conferred to Leith the idea of diffuse illumination of objects when making holograms of two-dimensional transparencies. This was unlikely, to say the least: Leith and Upatnieks had done this research in 1962, at a point when Stroke had only once met Leith, and in a group setting at that. ${ }^{38}$ In April 1964 Stroke wrote to the university news service to claim credit for originating and developing much of the Optics Group's holography and spatial filtering work, but retracted his claims after a meeting with IST administrators. ${ }^{39}$ Willow Run staff warily continued to maintain relations; Leith agreed to participate in a summer school on coherent optics organised by Stroke in 1964. In the course notes, Stroke cited the previous December's draft NSF proposal, without title, as a reference-creating the impression of earlier collaborative work between Leith and himself.

The most troubling event, according to the Willow Run researchers, occurred in the autumn of 1964. Returning from summer travel in September, Stroke learned of an experiment that Upatnieks had recently performed with a student on microscopy, in which they had enlarged images holographically. Stroke asked Leith for time in his laboratory to reproduce the results. When Stroke's request was rebuffed, he asked to borrow photographs of the results to use for his teaching at the University of Michigan, which Leith and Upatnieks, with reservations, provided. A week later he suggested to Leith that they present a joint paper on the work; this, too, they rejected. Leith, now mistrustful, specified by letter that the loaned photos were not to be circulated beyond Stroke's class. ${ }^{40}$ Stroke nevertheless wrote a paper himself based partly on Leith and Upatniek's results, and presented it at the Boston meeting that November-but with scarce mention of their production of the work. Stroke further misrepresented the origin of the research by displaying his own name on Upatniek's slides of a fly's wing and a paramecium both during the presentation of the paper, and in a press conference after the meeting. ${ }^{41}$ Towards the end of the accompanying press release he noted:

Aside from Dr Stroke and D. G. Falconer, a graduate assistant in the Physics Department at the University of Michigan, a number of their colleagues, associates and other experimenters are engaged in the development of lensless photography in view also of other 
applications at the University of Michigan. Among those are E. N. Leith, J. Upatnieks, D. Brumm and A. Funkhouser. ${ }^{42}$

Thus 'lensless photography' had been appropriated boldly, and Leith and Upatnieks of the Optics Group were publicly classified with Stroke's graduate students. Stroke published the photographs and the work as his own in other publications from that autumn. ${ }^{43}$

Willow Run Laboratory workers who had presented the preceding papers at the same session of the Boston meeting were aghast, and members of Stroke's own lab recall being surprised by his claims. ${ }^{44}$ Following a series of mutual recriminations, meetings with administrators and letters by Leith to journal editors, the Head of Electrical Engineering recommended that IST support for Stroke be phased out. ${ }^{45}$ Bypassing these attempts to defuse the behind-the-scenes disputes, George Stroke presented the affair as a case of inappropriate usurpation of seniority cloaked in secrecy:

Various rumours appear to have recently originated about some aspects of the 'lensless photography' work being carried out at the University of Michigan...In no way should Professor Stroke's apparent silence in the face of a one-sided spreading of rumours be interpreted as other than a traditional desire of a scientist and senior faculty member to maintain the dignity of the faculty and the University when faced with rumours apparently originating from junior staff...The extent of such collaborative efforts, carried out to a large part In a framework of military secrecy, cannot be revealed without infringement of national interests. It now appears that some one-sided advantage may have been taken by some party of the collaborative effort, in the face of Professor Stroke's strict adherence and respect for the secrecy rules. ${ }^{46}$

Stroke was a more practiced communicator than was Leith. He extended the same attention to subliminal messages in his holograms: when Leith was shown in the popular press demonstrating the hologram of a military tank, Stroke ensured that his own most widely seen image was with the hologram of a statue of Abraham Lincoln (Figures 2 and 3).

Similarly, Stroke's announcement of advances in colour holography showed a hologram of soldiers in front of a red, white and blue American flag.

Nor were Leith and Upatnieks the only parties at Willow Run with grievances: Karl Stetson wrote to the executive secretary of the Optical Society of America to complain that Stroke had plagiarized the holographic interferometry results that he had obtained with Robert Powell. ${ }^{47}$ Researchers beyond the University of Michigan also complained. Workers at Bell Telephone Laboratories privately asserted that Stroke had misrepresented his work with them. ${ }^{48}$ Adolf Lohmann found illustrations from his papers reproduced without attribution in a grant report by Stroke. ${ }^{49}$ Electron microscopist Albert Crewe, who loaned Stroke an image for experiments on 'holographic deblurring', denounced him for improperly claiming that the technique rendered the DNA helix visible. The controversy, publicly reported in Science in November 1971, tarnished not only Stroke's reputation, but that of electron microscopists, too, while Stroke proffered privately that the microscopists should be grateful for the publicity. ${ }^{50}$ The chemist Lawrence Bartell, citing the 'immense egos' of both Stroke and Crewe, subsequently published an account of their falling out from his personal experience. ${ }^{51}$ 


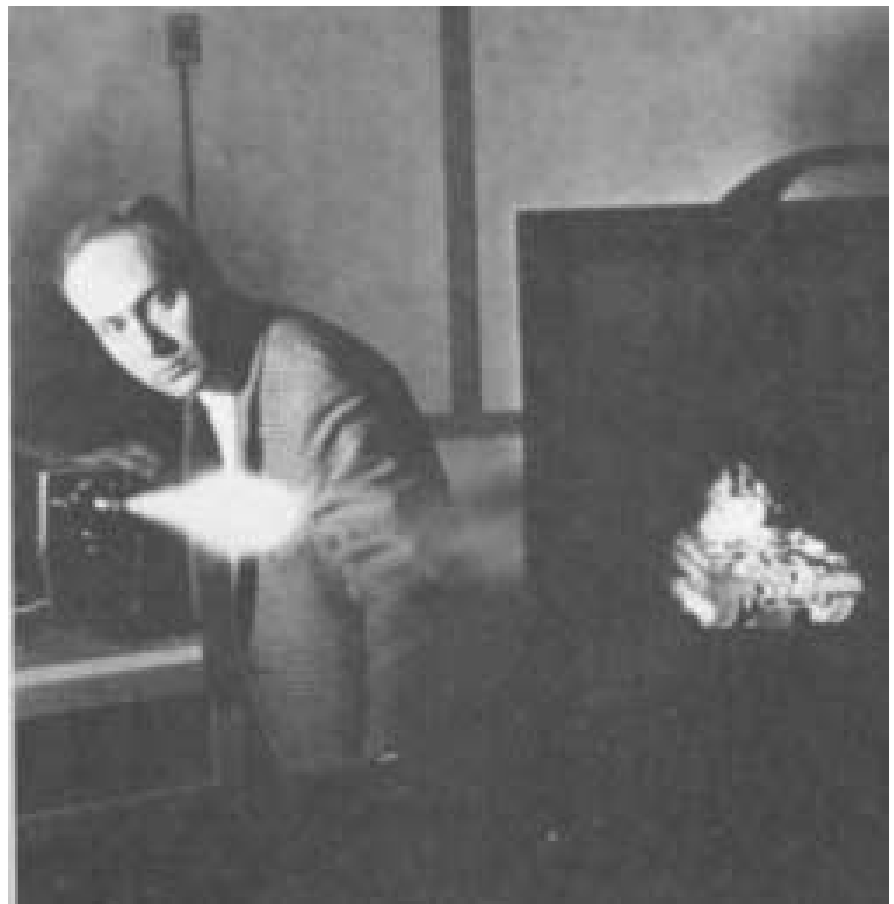

Figure 2 Emmett Leith, c.1966 (University of Michigan News Service).

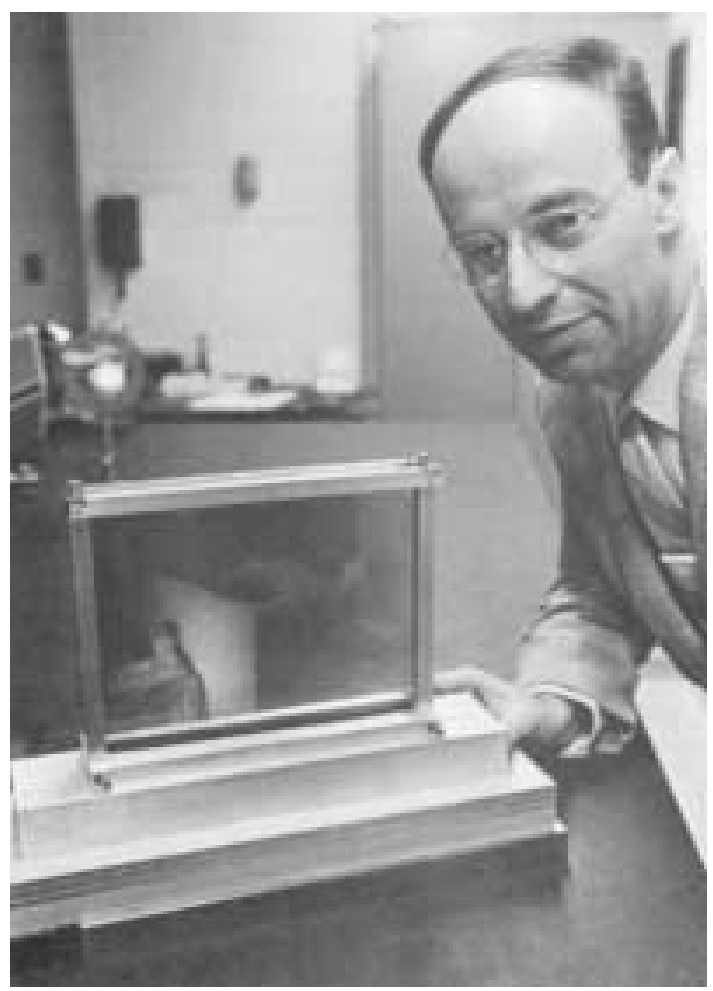

Figure 3 George Stroke, c.1966 (University of Michigan News Service). 
The President of the OSA read another such complaint that Stroke had denigrated Leith and Upatnieks in his abstract for an OSA meeting, but had then failed to support the allegations in the presentation itself, thereby insinuating unsubstantiated claims into a permanent record. He replied, 'We had other communications from people about the Stroke problem and it was discussed at the meeting of the Board of Directors of the OSA. It was felt that OSA should not take any action...it was our opinion that the truth of scientific status and priority is generally well recognized and the field recognizes the position of Leith and Upatnieks vs. Stroke' ${ }^{52}$

Yet this version of events remained largely an oral tradition limited to a single generation of practitioners. Stroke had himself taken the dispute beyond the University, and found effective means of broadcasting and publishing his version of events. He pleaded privately to the editor of the Journal of the Optical Society of America, in which he sought to publish results, that Leith and Upatnieks 'had been carrying out officially and under salary....as a joint project' work that was rightfully his own as Director of the, as yet, non-functional Electro-Optical Sciences Laboratory. ${ }^{53}$ His claims may have had some validity in the European context: there, a full professor commonly could claim co-authorship of a publication if he had specified the goal and scrutinized the first draft of a manuscript. Moreover, authorship would be limited to those holding a master's degree, or to an exceptional undergraduate or technician. Nevertheless, such intellectual appropriation did not occur for other Europeans working in the same field and having an obvious hierarchical relationship with their senior colleagues, such as Serge Lowenthal (working in Paris under André Maréchal), F. T. Arecchi (in Florence, under G. Toraldo di Francia) and Emil Wolf (in Edinburgh, under Max Born). ${ }^{54}$ The members of his laboratory report that Stroke developed a paternalistic relationship with them, but this never developed for his WRL colleagues who were already in place when he arrived. Yet his written claims seemed carefully crafted to be both ambiguous and misleading concerning such hierarchies.

Via informal lectures, conference presentations, papers, an academic monograph and then popular articles, Stroke publicized his version of the history of holography. In a survey of holography written for Technology Review in 1967, the biography supplied by Stroke stated that he had 'first initiated research in 3-D holography in 1962, and has since continuously stimulated much of the research in this field by numerous scientific contributions, the first book in the field and by world-wide lectures' ${ }^{55}$ His article provoked a response from E. G. Loewen, Director of the Grating and Metrology Lab at Bausch and Lomb in Rochester, NY, who accused Stroke of 'unsubstantiated slander in having accused Leith and Upatnieks of gross plagiarism'. 56

An excellent opportunity to launch his claims for a wide audience was Stroke's $A n$ Introduction to Coherent Optics and Holography, the first book and first attempt at outlining a history of the young subject. ${ }^{57}$ Announced publicly from the summer of 1964 and written during 1965-by which time relations with Willow Run had foundered and Stroke's own laboratory had been underway for only a few monthsStroke's book portrayed a genealogy of holography that minimised the work of Leith and Upatnieks and vaunted his own. 
The book led to public rebuke for Stroke. A review of his book by Emil Wolf, who had collaborated with Dennis Gabor and Max Born on the early writing of their canonical text Principles of Optics some 15 years earlier, savaged it as a hastily prepared 'first'. ${ }^{58}$ After illustrating a number of cases of 'misstatements, false mathematical arguments and confusing notation', he turned to the 'disturbing' attribution of credits:

Anyone familiar with the field of holography, or anyone who is not but who will take the trouble to check the literature, will know that one of the first major contributions to this field, after Gabor's pioneering publications, was the separation of the twin images by a clever arrangement first described in the published literature by E. N. Leith and J. Upatnieks. Yet this contribution is completely ignored in the first few sections of the chapter on holography and is played down elsewhere. Moreover, several figures in this book show the Leith-Upatnieks arrangement without acknowledgement. On the other hand, alleged contributions of the author are frequently stressed, even if they never reached the print...This sort of referencing, which presents unsupported claims and not a real reference at all, evokes a question of ethics. The reader should reflect on the scientific climate that would be created if other authors were to adopt such a way of referencing.

Wolf concluded, 'This is a very disappointing book. Its merit lies chiefly in making available reprints of Gabor's three pioneering papers on holography'. ${ }^{59}$ The review attracted the praise of the editor of Applied Optics, who intimated 'I'm not sure I would have the courage to carry such a review, considering the uproar that would probably ensue. We chose Gabor (who was rather non committal) as a way to evade backlash'.60

\section{Stroke and Gabor}

It was through Dennis Gabor, however, that Stroke's historiography was further promoted. George Stroke had first met Gabor in the summer of 1964, and an amicable and mutually beneficial relationship developed between them. Indeed, Gabor later recalled that George Stroke had been the first researcher to contact him after Leith's and Upatnieks' revived holography became known. Stroke began corresponding with Gabor regularly, and significantly offered one-quarter of the royalties for his book to Gabor, presumably in exchange for permission to include three of Gabor's seminal papers as appendices. Selling 3,665 copies in the first year alone-a respectable number for such a text-this proved profitable for both. ${ }^{61} \mathrm{He}$ also sought to limit contacts between, and to alienate, Gabor and Leith, on one occasion reporting 'a gross attempt at slander' of Gabor by another member of the Willow Run Labs, who inadvertently had had his letter displayed on a notice board near Stroke's office. ${ }^{62}$

Stroke pursued a relationship as confidante to Gabor. During 1966 and 1967, both were in the US, with Stroke making the transition during this period from the University of Michigan to his new post at SUNY Stony Brook, and Gabor consulting for about half the year at CBS Laboratories, where he was organizing a holography laboratory. Gabor began to rely on Stroke as an expert on the mushrooming literature and latest developments in laser holography, a part of the field in which Gabor himself had, as yet, no direct experience. ${ }^{63}$ 
George Stroke, as one of the few practitioners describing the historical trajectory of holography during the 1960s, was influential in presenting a nearly uncontested version of the subject to the wider public. He favoured what he described as 'broad and historical' accounts of holography, such as a Japanese seminar in 1967 about which he subsequently reported of himself, 'Dr. Stroke, a pioneering contributor to laser holography, discussed many of the varied developments for which he was responsible'. ${ }^{64}$ Dennis Gabor relied on Stroke's accounts for his own lectures and papers synthesizing an overview of the subject.

Leith still felt vulnerable in this battle of historiographies, given the hidden nature of the early work at Willow Run, and Stroke's highly effective public mis-citing of precedence. Leith continued in his own private attempts to present his version of events, writing to comment on Gabor's planned 1969 Royal Society discourse on holography and pointing out historical errors:

There are, however, two statements that distress me: that the explosion in holography was started in 1962 by E. N. Leith, J. Upatnieks, and G. W. Stroke, and that diffused illumination was conceived simultaneously by Leith, Upatnieks and by Stroke. Our diffused-illumination holography was started many months before Stroke came to U of M... ${ }^{65}$

Gabor wrote back a week later expressing his distress at being between the two 'hostile camps', and seeking historical compromise by bracketing Leith and Stroke from 1962, while giving Leith full credit for work before that time, a chronology unsupported by documentary evidence. Through early 1969, Gabor attempted to conciliate, stating that, despite his obvious ambition, 'I would never have judged George Stroke as a stealer of merits', and counselling generosity on Leith's part. ${ }^{66}$

\section{The Nobel Prize and Historiographical Validation}

Such personal contentions, driven by the common desire for professional recognition, have afflicted many episodes in science. However, the Stroke controversies were significant in that they shaped and distorted the early accounts of a significant scientific field that had been transformed by the achievements at the Willow Run Laboratories and the Vavilov Optics Institute, and one in which a growing number of observers were predicting the award of a Nobel Prize by the late 1960s. ${ }^{67}$ T. E. Allibone recalls:

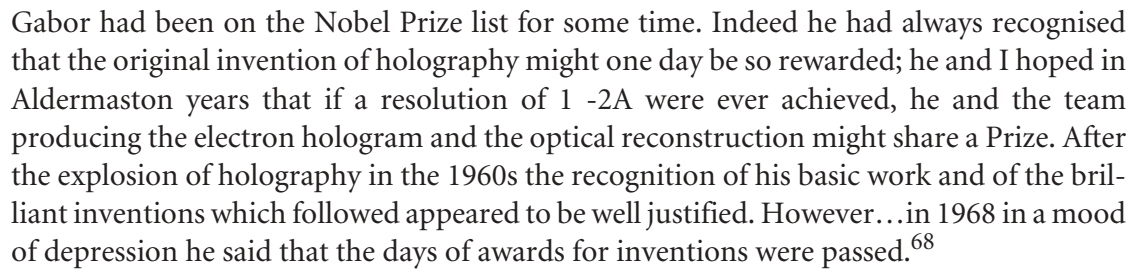

In later years, Stroke claimed to have been instrumental in gaining the Nobel Prize for Dennis Gabor by persistent lobbying. ${ }^{69}$ Adolf Lohmann has commented that Stroke may indeed have influenced the awarding of the Prize in subtle and more obvious ways. ${ }^{70}$ The Nobel Prizes are susceptible to cynical influence or manipulation without breaking its own rules and procedures. The Nobel Committee for physics sent out 
several hundred enquiries to a carefully selected cross-section of the physics community in the autumn of 1970. Recipients were requested to complete forms with the names of one, two or three worthy candidates for the Prize, to be returned by midJanuary 1971. Thereafter, the committee had some eight months to identify the most suitable candidate, or combination of candidates, and then to submit their proposal for acceptance by the full Physics Section of the Royal Academy of Sciences in Stockholm, Sweden. Once approved, the successful candidate was announced in early October. The opinions of the Nobel committee could be influenced in various ways:

- By submitting a strong proposal for the candidate if invited to do so by the committee members, i.e. if already acknowledged as a recognized participant in the subject, as George Stroke was.

- By an individual contacting those already known to be invited, namely previous Nobelists. Stroke notes that he lobbied physicists Alexandr Prokhorov and Alfred Kastler, winners of the Nobel Prize in 1964 and 1966, respectively.

- By promoting the candidate and his field, for example by review articles. In the years prior to Gabor's Nobel Prize, Stroke collaborated with him, especially in popularizations and surveys of the field that linked their names in historical accounts. ${ }^{71}$

In the case of the Nobel Prize for holography, Stroke publicly and privately promoted a collection of claims: first, that holography is an important, burgeoning field; second, that Gabor was the primary inventor; third, that Leith had made rather obvious extensions based merely on the availability of the laser; and fourth, that Stroke himself had created the modern field by introducing a mathematical treatment for a subcategory of the subject that he denoted 'Fourier transform holography'. In the Nobel Prize procedure of identifying one, two or three plausible candidates, Stroke thus vaunted a pair (Gabor and himself) while simultaneously deprecating a triplet (Gabor, Leith and anyone else) because if Leith were admitted to have made major contributions, then so had a handful of other individuals ahead of Stroke. This strategy required not only the career boosting common to many scientists, but also the disparagement of a formidable assortment of adversaries at the University of Michigan and beyond.

Beyond Gabor and the seminal Emmett Leith, a third claimant to the prize could well have included Yury Denisyuk or perhaps Juris Upatnieks. This triumvirate is uncontentious unless both Leith and Denisyuk are portrayed as being either unaware of possibilities or poorly motivated. Stroke actively disparaged Leith, and appears largely to have ignored, or belittled the generality, of Denisyuk's accomplishments. By contrast, Gabor himself observed that, had it not been for Leith's re-invention and extension, holography and Gabor's contribution would have been forgotten.

Whether or not Stroke's claim of overt influence with the Prize Committee is sustainable, there is no doubt that he publicized his version of historical events widely and to his own advantage. Stroke edited Gabor's Nobel Prize lecture, which provided an officially recognized version of the history of the subject to 1971. Stroke's two dense pages of amendments again emphasized his own contributions at the expense of Leith, Denisyuk and others. ${ }^{72}$ Although examples of press releases, newspaper reports and 
other public documents provided rather a different chronology, Gabor had little independent evidence at hand; he acquiesced and incorporated the changes that Stroke ardently counselled.

Following the prize, Stroke arranged for a visiting professorship for Gabor at the New York Institute of Technology. The two collaborated, too, on a National Science Foundation film on holography and other research. Gabor's subsequent popular writings continued to be influenced heavily by Stroke's historiography ${ }^{73}$ After Gabor's death in 1979, Stroke continued to write surveys of holography that linked himself with Gabor. $^{74}$

What can be made of these episodes? Beyond his influence on individual careers, George Stroke had longer-enduring effects on holography and its history. In the relationship between Dennis Gabor and George Stroke, both individuals gained recognition and status. Stroke vaunted Gabor's little-remembered work; in return, Stroke gained considerable status from his association with Gabor, crucially influencing the early historiography through the popular writings of Gabor and Winston Kock. ${ }^{75}$ The result has been a clouded history in which the crucial nature of the occupational context, professional relationships and intellectual evolution have been misrepresented.

However, the oral tradition sustained by frequent conferences on holography attended by a coterie of a few thousand participants created a simpler but enduring historiography. In it, Gabor and Leith (and latterly Yury Denisyuk) were portrayed as the 'fathers' of the subject and, as traditional in such tales, imbued with the qualities of genius, modesty and generosity-admittedly attributes well supported by the documentary evidence.

There are thus two coexisting but disconnected origin stories. One was kept alive by the oral accounts of practitioners active during the 1960s, and another in the public domain via published sources. The 'Stroke problem' was widely related and mythologized at conferences from which George Stroke was absent after the mid-1970s. While these stories served specific purposes — privately righting wrongs, serving as paradigms of bad science and even binding together social groups-they circulated in a narrow sub-culture and have faded for subsequent generations. The more recent anodyne, Stroke-free, oral tradition nevertheless tends to underplay the accomplishments of the first communities of holographers. However, by unravelling the priority claims and clarifying the actual events, institutional contexts and personal motivations, the history of holography (or holoscopy, wavefront reconstruction, wave photography and lensless photography) can be made meaningful to a wider audience.

\section{Acknowledgements}

The author acknowledges with gratitude the comments by John Krige, conversations with Ben Franks and Mark Ward, and the financial support of the Carnegie Trust for the Universities of Scotland, the British Academy, the Shearwater Foundation and a grant-in-aid from the Friends of the Center for the History of Physics at the American Institute of Physics. 


\section{Notes}

[1] Historical participants providing information included Norm Barnett; Lawrence Bartell; Stephen Benton; Douglas Brumm; H. John Caulfield; Gary Cochran; Frank Denton; Yury Denisyuk; Arthur Funkhouser; Donald Gillespie; Kenneth Haines; Guy Indebetouw; Tung Jeong; Antoine Labeyrie; Emmett Leith; Carl Leonard; Adolf Lohmann; George Stroke; and, Richard Zech. Imperial College archives the papers of Dennis Gabor and Gordon Rogers. The MIT Museum holds the records of the New York Museum of Holography, which had collected various historical files including papers from Gabor's American office. The Bentley Historical Library has personnel and administrative files for the University of Michigan. Personal collections of Cochran, Funkhouser, Leith and Leonard were also studied.

[2] On the reinvention of holography by different audiences, see Sean F. Johnston, 'Holography: From Science to Subcultures' and Sean F. Johnston, 'Shifting Perspectives: Holography and the Emergence of Technical Communities'.

[3] Denisyuk's account has been recorded in one of the few refereed historical papers on holography, in Yu N. Denisyuk and V. Gurikov, 'Advancement of Holography, Investigations by Soviet Scientists,' 127-32.

[4] Gabor later recalled, 'When I started holography, neither I nor my assistant, Ivor Williams, had any experience in optics, yet we got it going in half a year.' Dennis Gabor, 3 June 1967 letter communication to Peter Goldmark, IC GABOR LA/9.

[5] Dennis Gabor, Great Britain Patent No. 685,286 (17 December 1947); Gabor, 'A New Microscopic Principle,' 777-8; and Gabor 'Microscopy By Reconstructed Wavefronts,' 454-87.

[6] Sir Lawrence Bragg FRS (1890-1971) had worked with his father William on x-ray analysis of crystal structure, winning them the Nobel Prize in 1915. He subsequently was professor of physics at the University of Manchester for 18 years, Director of the National Physical Laboratory 1937-1939, and then held the Cavendish chair in Physics at Cambridge until 1953.

[7] Readable and accurate accounts of the underlying principles are given, for example, in Denisyuk, Fundamentals of Holography; and Saxby, Manual of Practical Holography.

[8] Dennis Gabor, 22 March 1954 letter communication to T. E. Allibone, IC GABOR MA/6/1.

[9] Allibone, 'White and Black Elephants at Aldermaston,' 179-92.

[10] T. E. Allibone, 13 September 1961 letter communication to Dennis Gabor, IC GABOR MS/6/3.

[11] Besides Gabor and his co-workers, the principal publications during the 1950s were by W. L. Bragg and G. L. Rogers in Britain, P. Kirkpatrick, H. M. A. El Sum and A. Baez in America, and A. Lohmann in Germany.

[12] Project MICHIGAN, a broad programme of battlefield surveillance established as the second phase of an Army, Navy and Air Force Research Program administered by the Army Signal Corps, was funded until the late 1960s. It included research in radar, infrared, acoustics, optics, guidance and data processing. The approval of Project MICHIGAN by the University led to a reorganisation of its facilities as a 'center for classified research' at the Willow Run Airport (University Michigan Board of Regents Proceedings May 1953 and February 1954). Administrative records are now archived in the Bentley Historical Library, and declassified reports available from some participants.

[13] Leith was promoted successively to Graduate Research Assistant (1955), Research Associate in (1956), Research Engineer (1965) and full Professor (1968). His most careful historical account is published in Leith 'A Short History of the Optics Group of the Willow Run Laboratories'. Leith's account of the genesis of holography was the subject of a belated doctoral dissertation, Leith, The Origin and Development of the Carrier Frequency and Achromatic Concepts in Holography. A number of the WRL Optics Lab workers studied for PhDs after making important contributions to holography.

[14] Emmett N. Leith, 22 January 2003 interview communication to SFJ, SFJ collection.

[15] Emmett N. Leith (22 May 1956). 'A data processing system viewed as an optical model of a radar system’. Memo to W. A. Blikken of Willow Run Laboratories, Leith collection. 
[16] Cutrona, Leith, Palermo et al., 'Optical Data Processing and Filtering Systems,' 386-400. Willow Run was also the site of development of the first ruby maser (1958) and multi-spectral remote imaging (1960s).

[17] Leith and Upatnieks, 'New Techniques in Wavefront Reconstruction,' 1469.

[18] W.G. Dow, 30 November 1962 letter communication to George W. Stroke, Bentley Historical Library, Institute of Science and Technology Box 21: Personnel. See Figure 1 for the administrative structure at the University of Michigan.

[19] 'IST establishes lab in new study field'. Ann Arbor News, 2 October 1963, 37.

[20] George R. Harrison (1898-1979) spent his career at MIT, becoming Professor of Experimental Physics there in 1930 and Dean of Science in 1942 until his retirement in 1964. He was head of the MIT Spectroscopy Laboratory, chief of the Optics Division of the National Defense Research Committee (NDRC) during the Second World War, and later head of the Office of Scientific Research and Development (OSRD) Office of Field Service.

[21] Harrison and Stroke, 'Interferometric Control of Grating Ruling with Continuous Carriage Advance,' 112-21.

[22] Aspray, George Wilhelm Stroke, Electrical Engineer, an Oral History Conducted in 1993 by William Aspray.

[23] Stroke suggested that mere jealousy was at the root of their conflict, recalling, 'I was the only person in his career who ever became a professor from among his many, many brilliant collaborators. He could not stand it' (Ibid.). Stroke later provided an authoritative 350 page article to the Handbuch Der Physik, 'encroaching,' according to a colleague, on Harrison's own work. Stroke, 'Diffraction Gratings,' 26-754; Frank Denton, 1 May 2003 telephone communication to SFJ, SFJ collection.

[24] Leith and Upatnieks, 'Wavefront Reconstruction with Continuous-tone Transparencies,' 522.

[25] This mythology was augmented in no small part by Dennis Gabor, who said in his Nobel Prize speech, 'When the laser became available in 1962, Leith and Upatnieks could at once produce results far superior to mine, by a new, simple and very effective method of eliminating the second image...made possible by the great coherence length of the helium-neon laser.' Gabor, 'Holography, 1948-1971,' 169-201. The laser's coherence was, of course, essential for producing holograms of three-dimensional objects, but not the two-dimensional transparencies used by investigators up to 1963 . This mis-telling of the story, unconscious as it almost certainly was, nevertheless provided a satisfying explanation for why the directions taken up at Willow Run had not been pursued earlier by Gabor and his collaborators.

[26] Stetson and Marks, 'Use of a Helium-Neon Laser as a Light Source'; Emmett N. Leith, 22 Jan 2003 interview communication to SFJ, SFJ collection; Juris Upatnieks, 25 June 2003 email communication to SFJ, SFJ collection.

[27] Juris Upatnieks, 24 June 2003 email communication to SFJ, SFJ collection; Emmett N. Leith, 22 Jan 2003 interview communication to SFJ, SFJ collection.

[28] Dulberger and Wixom, 'Lensless Optical System Uses Laser: Opaque 3-D Objects May be Imaged without Lenses Using Reflected Light'. A similar article appeared shortly afterward: 'Laser Photographic Process Uses No Lenses, Produces 3-D Images'.

[29] Lutz, 'New Discoveries at Michigan Universities,' 1.

[30] Novotny, 'The Little Train that Wasn't,' 86-9.

[31] The term 'lasography' failed to win converts ('3-D Lasography - the Month Old Giant', Laser Focus, 1 January 1965). On his claim of the coining of 'holography', see Rogers, 'The Word "Holography",' $57-8$.

[32] William M. Brown, George W. Stroke, and Emmett N. Leith, 10 December 1963 memo communication to file, Bentley Historical Library Institute of Science and Technology Box 21: Electro-Optical Lab.

[33] Emmett N. Leith, Summer 1965 memo communication to WRL administrators, Leith collection. 
[34] George W. Stroke, 30 September 1963 memo communication to J. T. Wilson, Bentley Historical Library Institute of Science and Technology Box 21: Electro-Optical Lab.

[35] Emmett N. Leith (28 May 1963). 'Proposal for Applications of the Wavefront Reconstruction Technique'. Grant proposal ORA-63-1255-PB1, Leith collection.

[36] George W. Stroke, 16 April 1964 letter communication to C. G. Brown, Leith collection.

[37] J. T. Wilson, c.March 1964 communication to A. G. Norman, Bentley Historical Library Institute of Science and Technology Box 21: Electro-Optical Lab.

[38] It could be argued that Stroke's claim was further undermined by the fact that (microwave) holography of diffusely reflecting 3D objects had in effect been discussed in Leith's 1956 memo, although Leith did not at that time conceive that the same might be done at optical frequencies with the yet-to-be invented laser source.

[39] George W. Stroke, 11 April 1964 letter communication to Charles W. Wixom, Leith collection.

[40] Emmett N. Leith, 20 October 1964 letter communication to George W. Stroke, Leith collection.

[41] Stroke, presented at the Symposium on Optical and Electro-Optical Information Processing Technology, Boston, MA (unpublished), 1964.

[42] Stroke, 'New Optical Principle of "Lensless" X-ray Microscopy'.

[43] Stroke and Falconer, 'Attainment of High Resolutions in Wavefront-Reconstruction Imaging,' 306-9.

[44] Frank Denton, 1 May 2003 telephone communication to SFJ, SFJ collection; Arthur Funkhouser, 9 Apr 2003 email communication to SFJ, SFJ collection.

[45] Emmett N. Leith, 30 November 1964 letter communication to George W. Stroke, Leith collection; Emmett N. Leith, c Summer 1965 memo communication to to WRL administrators, Leith collection; Emmett N. Leith, 17 March 2003 email communication to SFJ, SFJ collection; H. W. Farris, 21 January 1965 communication to J. T. Wilson, Bentley Historical Library Institute of Science and Technology Box 21: Electro-Optical Lab. The bulk of the papers in the Electro-Optical Lab file concern the Stroke allegations between 1964 and 1967. Indeed, relations deteriorated further; following disputes between Stroke and his technicians, secretary and graduate students, U-M administrators dissolved his Electro-Optics Lab; academically isolated, he resigned in July 1967 and took a post at the State University of New York at Stony Brook. W.G. Dow, 26 January 1967 memo communication to George W. Stroke, Bentley Historical Library Institute of Science and Technology Box 21: ElectroOptical Lab.

[46] Stroke, 'To Whom It May Concern: Lensless Photography Work at the University of Michigan'.

[47] Karl A. Stetson, 7 March 1966 communication to Mary A. Warga, Bentley Historical Library Institute of Science and Technology Box 21: Electro-Optical Lab.

[48] J. Snell, 4 April 1966, letter communication to R. Evaldson, Leith collection.

[49] Adolf W. Lohmann, 19 August 2003 fax communication to SFJ, SFJ collection; Stroke, 'Optical Image Deblurring Methods,' 14-20.

[50] Nelson, 'DNA Double Helix: Photo Sends Controversy Spiraling,' 800-1; George W. Stroke, telegram communication to Dennis Gabor, IC Gabor MS/15.

[51] Bartell, 'A Brief History of Holographic Hubris and Hilarity,' 53-6.

[52] Van Zandt Williams, 23 March 1966 letter communication to John Shewell, Bentley Historical Library Institute of Science and Technology Box 21: Electro-Optical Lab.

[53] George W. Stroke, 12 December 1964 letter communication to David L. MacAdam, Leith collection.

[54] Adolf Lohmann, 4 November 2003 email communication to SFJ, SFJ collection.

[55] Stroke, 'Recent Advances in Holography,' 16-22.

[56] E. G. Loewen, 1967 communication to Technology Review editor, Bentley Historical Library Institute of Science and Technology Box 21: Electro-Optical Lab.

[57] Stroke, An Introduction to Coherent Optics and Holography.

[58] Wolf had made a consulting visit to the U-M in December 1963, after Stroke had suggested to the IST Director that Wolf be sounded out as a possible addition to the University of 
Michigan faculty to add prestige to their efforts. George W. Stroke, 12 December 1963 memo communication to J. T. Wilson, Bentley Historical Library Institute of Science and Technology Box 21: Electro-Optical Lab.

[59] Stroke, An Introduction to Coherent Optics and Holography, reviewed by Emil Wolf in Journal of the Optical Society of America, 57. Another reviewer observed, 'The chapter on holography lists 94 references which are noted so often as to make them useless. The continual references to the author's own papers are particularly annoying,' Morgenstern, 'Review of An Introduction to Coherent Optics and Holography'.

[60] John M. Howard, 5 May 1967 letter communication to Emmett N. Leith, Leith collection. Applied Optics was to become the principal organ for publications on holography.

[61] George W. Stroke, 23 April 1967 communication to Dennis Gabor, IC GABOR MR7/5. Gabor was approaching compulsory retirement as professor, although permitted a two-year extension of his chair until 1967. Having entered academe late in life, Gabor was conscious that his pension would be small, and planned to augment his income with consultancies, as he had done periodically since the 1950s.

[62] See IC Gabor ML/4 for correspondence between Stroke and Gabor, Gabor and Leith, and Leith and Adam Kozma, the latter being the senior WRL researcher who was studying for a $\mathrm{PhD}$ at Imperial College from 1966 and whose letter was made public.

[63] Dennis Gabor, 1966-67 letter communications to Peter Goldsmith, IC GABOR LA/9.

[64] Stroke, 'U.S.-Japan Seminar on Holography, Tokyo and Kyoto, 2-6 October 1967,' 622.

[65] Emmett N. Leith, 21 February 1969 letter communication to Dennis Gabor, IC Gabor $\mathrm{ML} / 4$.

[66] Dennis Gabor, 22 April 1969 letter communication to Emmett N. Leith, Leith collection.

[67] Based on extant personal letters to Gabor, there were hints from friends such as H. M. A. El-Sum: 'While in Stockholm, I heard of other anticipated nice things which are kept quiet at the present, and I hope to be the first to congratulate you next year for winning the biggest of all international awards.' H. M. A. El-Sum, 26 Nov 1969 letter communication to Dennis Gabor, IC GABOR EM/8.

[68] Allibone, 'Dennis Gabor 1900-1979,' 107-40, 135.

[69] Aspray, George Wilhelm Stroke, Electrical Engineer, an oral history conducted in 1993 by William Aspray.

[70] Adolf W. Lohmann, 9 October 2003 fax communication to SFJ, SFJ collection.

[71] Gabor, Kock, and Stroke, 'Holography,' 11-23. Significantly, the only accounts that portrayed Stroke's version of events were his own writings, the historical narratives that he edited with Dennis Gabor, and a popular book by one of his collaborators (Kock, Lasers and Holography; an Introduction to Coherent Optics). Win Kock, who had worked on early electronic music, microwave lenses, acoustics and solid state physics in a distinguished career at firms such as Bell Telephone Laboratories, the Bendix Corporation and NASA's Electronics Research Center, first met Stroke in 1967 when he was invited by him to take part in a US-Japanese seminar on holography funded by the NSF. Kock, Stroke and Dennis Gabor collaborated on a popular article in the early 1970s, when Kock himself was near retirement, Gabor, Kock, and Stroke, 'Holography'. Kock's idiosyncratic account-which, like Gabor's historical summaries, was heavily reliant upon Stroke's selection and interpretation of the technical literature-attributes Denisyuk's research to Stroke and co-workers, and indeed makes no mention of non-American work. One of his subsequent books attracted a withering review; see Latta and Leith, 'Review of Engineering Applications of Lasers and Holography,' 203-4.

[72] George W. Stroke, 26 November 1971 letter communication to Dennis Gabor, IC Gabor MS/ 15.

[73] See, for example, George W. Stroke, telegram communication to Dennis Gabor, IC Gabor MS/15; and Gabor, Holographie 1973.

[74] E.g. Stroke, 'Optical Engineering'. 
[75] Stroke's An Introduction to Coherent Optics and Holography in two editions, and Kock's Lasers and Holography; An Introduction to Coherent Optics supporting Stroke's claims, have remained two of the most widely available books on holography.

\section{References}

Allibone, T. E. 'White and Black Elephants at Aldermaston.' Journal of Electronics and Control 4 (1958): 179-92.

Allibone, T. E. 'Dennis Gabor 1900-1979.' Biographical Memoirs of Fellows of the Royal Society 26 (1980): 107-40, 135.

Aspray, William. George Wilhelm Stroke, Electrical Engineer, an oral history conducted in 1993 by William Aspray. New Brunswick, NJ: IEEE History Center, Rutgers University, 1993.

Bartell, Lawrence S. 'A Brief History of Holographic Hubris and Hilarity.' The Chemical Intelligencer (October 1998): 53-6.

Cutrona, L. J., E.N. Leith, C. J. Palermo, et al. 'Optical Data Processing and Filtering Systems.' IRE Transactions on Information Theory IT-6 (1960): 386-400.

Denisyuk, Yu N. Fundamentals of Holography. (Translated and revised from the 1978 Russian edition.) Moscow: Mir, 1984.

Denisyuk, Yu N., and V. Gurikov. 'Advancement of Holography, Investigations by Soviet Scientists.' History and Technology 8 (1992): 127-32.

Dulberger, Leon H., and Charles Wixom. 'Lensless Optical System Uses Laser: Opaque 3-D Objects May be Imaged without Lenses Using Reflected Light.' Electronics, 27 December 1963, 15.

Gabor, Dennis. Great Britain Patent No. 685,286 (17 December 1947)

. 'A New Microscopic Principle.' Nature 161 (1948): 777-8.

- 'Microscopy by Reconstructed Wavefronts.' Proceedings of the Royal Society of London, Series A 197 (1949): 454-87.

. 'Holography, 1948-1971.' In Les Prix Nobel En 1971, edited by Nobel Prize Committee. Stockholm: Imprimerie Royale P. A. Norstedt \& Sonner, 1971, pp. 169-201.

- Holographie 1973: Vortrag, gehalten an dem Mentorenabend der Carl Friedrich von Siemens Stiftung in München-Nymphenburg am 15. Juni 1973. Munich: Die Stiftung, 1973.

Gabor, Dennis, W. E. Kock, and George W. Stroke. 'Holography.' Science 173 (1971): 11-23.

Harrison, G. R., and G. W. Stroke. 'Interferometric Control of Grating Ruling with Continuous Carriage Advance.' Journal of the Optical Society of America, 45 (1955): 112-21.

'IST Establishes Lab in New Study Field.' Ann Arbor News, 2 October 1963, 37.

Johnston, Sean F. 'Holography: From Science to Subcultures.' Optics \& Photonics News 15 (2004).

- 'Shifting Perspectives: Holography and the Emergence of Technical Communities.' Technology \& Culture (2004, submitted).

Kock, Winston E. Lasers and Holography; an Introduction to Coherent Optics. Garden City, NY: Doubleday, 1969.

'Laser Photographic Process uses no Lenses, Produces 3-D Images.' Science Fortnightly 1 (9) (December 1963): 1-2, 25 .

Latta, John N., and Emmett N. Leith. 'Review of Engineering Applications of Lasers and Holography by Winston E. Kock'. Journal of the Optical Society of America 69 (1979): 203-4.

Leith, Emmett N. 'The Origin and Development of the Carrier Frequency and Achromatic Concepts in Holography.' Ph.D. diss., Wayne State University, 1978. . 'A Short History of the Optics Group of the Willow Run Laboratories.' In Trends in Optics. Vol. 3, edited by A. Consortini. New York: Academic Press, 1996, pp. 1-26.

Leith, Emmett N., and Juris Upatnieks. 'New Techniques in Wavefront Reconstruction.' Journal of the Optical Society of America 51 (1961): 1469.

Leith, Emmett N., and Juris Upatnieks. 'Wavefront Reconstruction with Continuous-tone Transparencies.' Journal of the Optical Society of America 53 (1963): 522. 
Lutz, William W. 'New Discoveries at Michigan Universities.' The Detroit News-The Passing Show, 23 February 1964, 1.

Morgenstern, Arthur L. 'Review of An Introduction to Coherent Optics and Holography by George W. Stroke'. Electronics, 16 May 1966.

Nelson, Bryce. 'DNA Double Helix: Photo sends Controversy Spiraling.' Science 173 (1971): 800-1.

Novotny, George V. 'The Little Train that Wasn't.' Electronics 37 (30) (30 November 1964): 86-9.

Rogers, G. L. 'The Word “Holography”.' Scientific Research (1968): 57-8.

Saxby, Graham. Manual of Practical Holography. Oxford: Focal Press, 1991.

Stetson, Karl A., and J. M. Marks. 'Use of a Helium-Neon Laser as a Light Source in Processing Sidelooking Radar Data', DDC No AD 336356.

Stroke, George W. 'New Optical Principle of "Lensless" X-ray Microscopy.' Press release for Symposium on Optical and Electro-Optical Information Processing. Boston, MA, 10 November 1964, Leith collection.

. 'To Whom it May Concern: Lensless Photography Work at the University of Michigan.' News release, Leith collection, April 1965.

- An Introduction to Coherent Optics and Holography. New York: Academic Press, 1966.

—. 'Diffraction Gratings.' In Handbuch der Physik, edited by S. W. Flugge. Berlin: Springer, 1967, pp. 26-754.

. 'Recent Advances in Holography.' Technology Review 69 (1967): 16-22.

. 'U.S.-Japan seminar on holography, Tokyo and Kyoto, 2-6 October 1967.' Applied Optics 7 (1968): 622.

. 'Optical Image Deblurring Methods.' Naval Research Reviews (1971): 14-20.

-. 'Optical Engineering.' Encyclopaedia Britannica Yearbook of Science and the Future. London: Britannica, 1980.

Stroke, George W., and D. G. Falconer. 'Attainment of High Resolutions in Wavefront-reconstruction Imaging.' Physics Letters 13 (1964): 306-9.

'3-D Lasography—-the Month Old Giant'. Laser Focus, 1 January 1965, 11.

Wolf, Emil. 'Review of An Introduction to Coherent Optics and Holography by George W. Stroke'. Journal of the Optical Society of America 57 (1967): 405-6. 